Author(s): Submitted to:

Edward D. Esparza, Howard Stacy, and Jerry Wackerle

27th Department of Defense Explosive Safety Seminar 20-22 August 1996

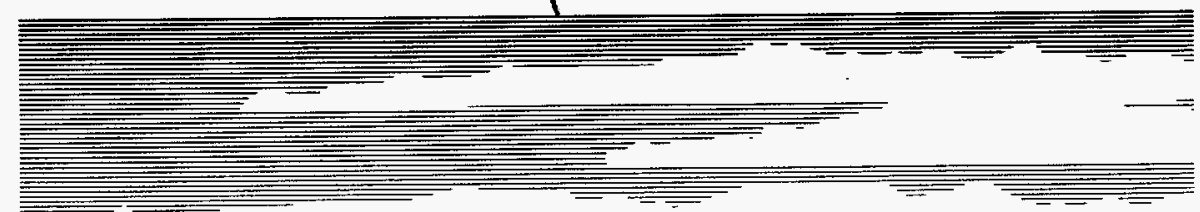

Los Alamos National Laboratory, an affirmative action/equal opportunity employer, is operated by the University of California for the U.S. Department of Energy under contract W-7405-ENG-36. By acceptance of this article, the publisher recognizes that the U.S. Government retains a nonexclusive, royalty-free license to publish or reproduce the published form of this contribution, or to allow others to do so, for U.S. Government purposes. The Los Alamos National Laboratory requests that the publisher identify this article as work performed under the auspices of the U.S. Department of Energy. 


\section{DISCLAIMER}

Portions of this document may be illegible in electronic image products. Images are produced from the best available original document. 


\section{DISCLAIMER}

This report was prepared as an account of work sponsored by an agency of the United States Government. Neither the United States Government nor any agency thereof, nor any of their employees, makes any warranty, express or implied, or assumes any legal liability or responsibility for the accuracy, completeness, or usefulness of any information, apparatus, product, or process disclosed, or represents that its use would not infringe privately owned rights. Reference herein to any specific commercial product, process, or service by trade name, trademark, manufacturer, or otherwise does not necessarily constitute or imply its endorsement, recommendation, or favoring by the United States Government or any agency thereof. The views and opinions of authors expressed herein do not necessarily state or reflect those of the United States Government or any agency thereof. 


\title{
Proof Testing of an Explosion Containment Vessel
}

\author{
by \\ Edward D. Esparza, P.E. \\ Engineering Consultant \\ San Antonio, Texas \\ and \\ Howard Stacy \\ Jerry Wackerle \\ Los Alamos National Laboratory \\ Los Alamos, New Mexico
}

27th Department of Defense Explosives Safety Seminar

20-22 August 1996

\begin{abstract}
A steel containment vessel was fabricated and proof tested for use by the Los Alamos National Laboratory at their M-9 facility. The HY-100 steel vessel was designed to provide total containment for high explosives tests up to $22 \mathrm{lb}(10 \mathrm{~kg})$ of TNT equivalent. / The vessel was fabricated from an 11.5-ft diameter cylindrical shell, 1.5 in thick, and 2:1 elliptical ends, 2 in thick. Prior to delivery and acceptance, three types of tests were required for proof testing the vessel: a hydrostatic pressure test, air leak tests, and two full design charge explosion tests. The hydrostatic pressure test provided an initial static check on the capacity of the vessel and functioning of the strain instrumentation. The pneumatic air leak tests were performed before, in between, and after the explosion tests. After three smaller preliminary charge tests, the full design charge weight explosion tests demonstrated that no yielding occurred in the vessel at its rated capacity. The blast pressures generated by the explosions and the dynamic response of the vessel were measured and recorded with thirty-three strain channels, four blast pressure channels, two gas pressure channels, and three displacement channels. This paper will present an overview of the test program, a short summary of the methodology used to predict the design blast loads, a brief description of the transducer locations and measurement systems, some of the hydrostatic test strain and stress results, examples of the explosion pressure and dynamic strain data, and some comparisons of the measured data with the design loads and stresses on the vessel.
\end{abstract}




\section{INTRODUCTION}

A steel containment vessel for use by the Los Alamos National Laboratory (LANL) at their M-9 facility was designed, fabricated and proof tested under contract by Southwest Research Institute. The HY-100 steel vessel was designed to provide total containment for high explosives tests up to $22 \mathrm{lb}(10 \mathrm{~kg})$ of TNT equivalent. At the 25th DoD Explosives Safety Seminar, a paper discussing the design requirements of the vessel, the design approach and the fabrication of the various components was presented by Polcyn, et al ${ }^{[1]}$. The structural design of the vessel consisted of designing the cylindrical shell, elliptical end caps, and solid reinforced concrete floor of the vessel to resist the design blast loads. Fragment shields were designed to protect the shell from small high velocity metal fragments which were expected to be generated during some of the operational explosives tests planned for the vessel. Also, the fatigue life of the cylindrical shell, which was considered representative of the fatigue life of the entire vessel, was checked against the design requirement. Simplified dynamic analysis procedures based on single degree-of-freedom (DOF) and three DOF "equivalent" systems were used to calculate the elastic deflections of complex vessel structural components at critical locations caused by the internal blast loads. A static finite element analysis was used to determine the shape function of the most complex vessel structural components and to relate the peak stresses in the components to the peak deflections calculated in the simplified dynamic analysis. Oswald, et $\mathrm{al}^{[2]}$, describes in much more detail the design of the containment vessel. In addition, all of the detailed design calculations and fabrication drawings are found in Reference 3. Oswald, et al ${ }^{[2]}$, also assessed how realistic the design procedure used was by comparing the calculated maximum dynamic stresses at key locations in the vessel to the stresses obtained from the strain data recorded on the proof tests. In addition, Reference 2 includes the results of post test dynamic finite element analysis for one of the elliptical end caps.

The vessel was fabricated from an $11.5-\mathrm{ft}$ diameter cylindrical shell, 1.5 in thick, and 2:1 elliptical ends, 2 in thick. Figure 1 shows two external views of the vessel. The forward end cap contains a 4 foot by 7 foot hydraulically operated blast door. Eleven 10 inch diameter viewports with replaceable layered polycarbonate/tempered glass panes were provided around the vessel. The vessel also has several other penetrations for cable pass-through, gas and vacuum lines, drainage, and air inlet and outlet. Reference 3 provides a more detailed description of the vessel. After fabrication and prior to delivery and acceptance of the vessel by Los Alamos, three types of tests were required for proof testing the vessel: a hydrostatic pressure test, air leak tests, and two full design charge explosion tests.

\section{DESIGN BLAST LOADS METHODOLOGY}

The blast pressures from a contained detonation of a high explosive charge consist of both a shock loading phase and a quasi-static gas loading phase. The shock phase, which occurs first, includes a pressure pulse from the initial shock wave generated by the detonation and several subsequent pressure pulses from the reflections of the shock wave off surfaces in the vessel. The shock loading phase becomes quite complex as normal and oblique reflections and re-reflections load a given surface of the vessel. In particular, reflections and focusing of the 


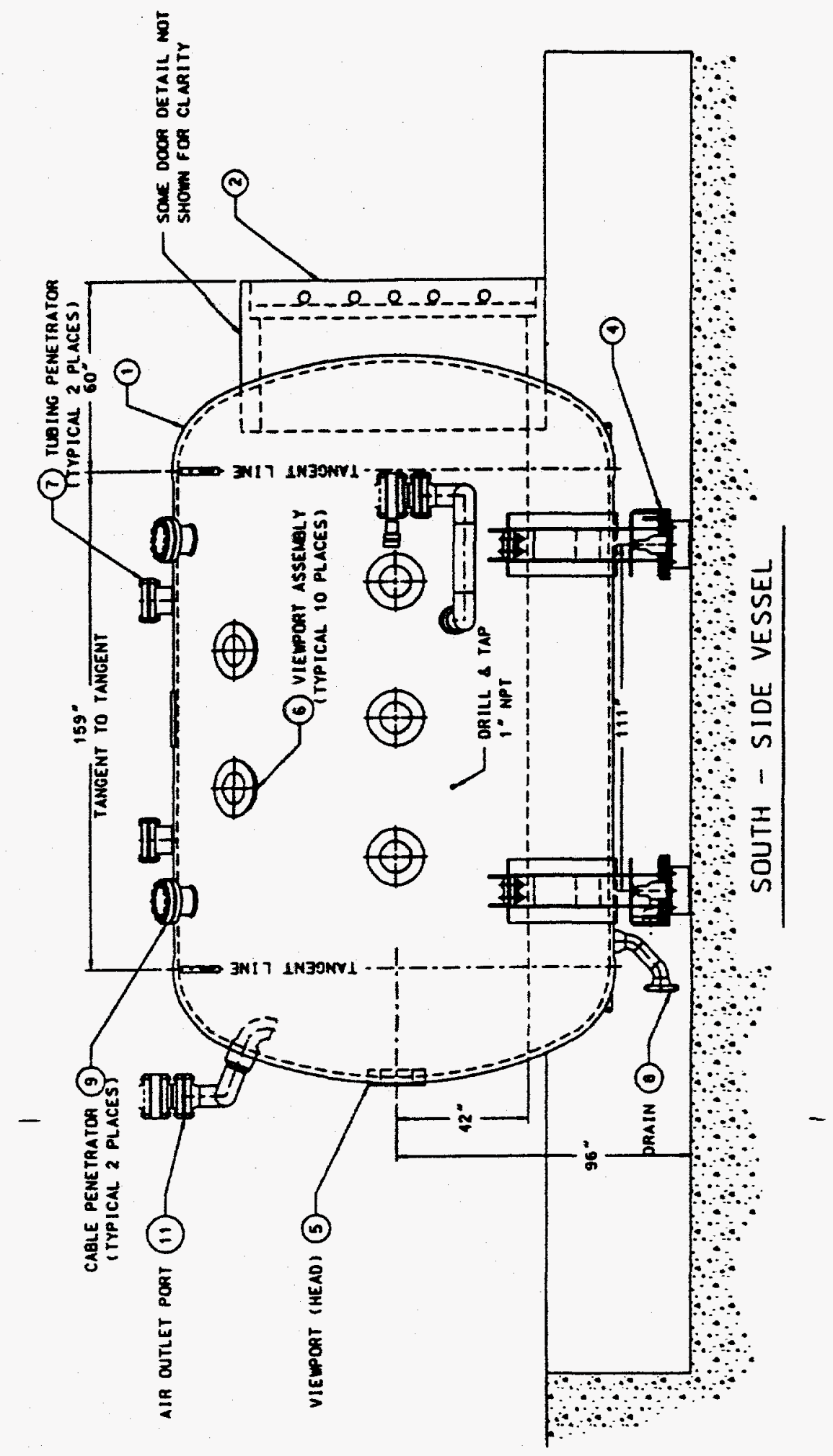

Figure 1. Elevation View of the LANL Containment Vessel 
shock wave can significantly enhance the shock pressure history on a particular section of the vessel. The gas pressure phase becomes apparent 10 to $20 \mathrm{~ms}$ (milliseconds) after the detonation when the pressure pulses from shock wave reflections decrease in amplitude. The gas pressure is caused by the large quantity of gas products generated by the explosion into the contained volume of the vessel and by the heat produced by the explosion, which increases the temperature and pressure of the gas mixture within the fixed volume of the vessel. Generally, the peak amplitude of the gas pressure is significantly smaller than the peak amplitude of the shock pressure. However, in a fully contained volume such as the blast containment vessel, the time duration of the gas pressure phase will be much longer than the time duration of the shock loading phase.

Figures 2 and 3 show the blast pressure histories used to design the cylindrical shell and the elliptical end caps, respectively, of the LANL containment vessel. These blast pressure histories were assumed to be uniform over the entire shell and end cap surfaces as a simplifying design assumption. The design pressure histories were estimated based on blast loads measured by Esparza and White ${ }^{[4]}$ in three vessels of similar geometry at the DOE Mound Laboratory and blast predictive methodologies including the then current version of the engineering computer code BLASTINW ${ }^{[5]}$. The blast loads in the Mound Laboratory vessels were first predicted as best as possible with the BLASTINW code, which required that the vessel be modelled as a rectangular box, and then these pressure histories were empirically adjusted to match the measured blast loads. Once reasonable correlations were obtained between the calculated and the measured data for the Mound vessels, the same methodology was repeated for the LANL vessel, which has a smaller volume and larger design charge weight than the Mound Laboratory vessels. The blast pressure-time history prediction for the cylindrical shell required less adjustments as compared to the prediction for the elliptical end caps. This probably occurred because the required simplification of the circular vessel cross section as an "equivalent" square in the BLASTINW code caused less distortion of the calculated shock pressure history on the cylindrical shell than on the end caps. As indicated by the Mound test data, the cylindrical shape of the vessel causes a significant amount of focusing of the shock waves along the longitudinal axis of the vessel.

The gas pressure phase of the blast load, which applies a uniform pressure throughout the entire vessel, was idealized as reaching a peak $10 \mathrm{~ms}$ after the detonation and remaining constant after that time. The peak gas pressure was determined from empirical curves in Reference 6 that relate the gas pressure to the ratio of the TNT-equivalent explosive weight to confined volume. Because of the short natural periods of the vessel components (less than 10 milliseconds), and the low ratio of peak gas pressure to peak shock pressure, the gas pressure did not contribute significantly to the peak dynamic response of the blast resistant components in the vessel. The details of the internal blast load prediction methods are discussed in Reference 3.

\section{SUMMARY OF TESTS}

Three types of tests were required to proof test the containment vessel: a hydrostatic pressure test, air leak tests, and several explosion tests including two full design charge weight 


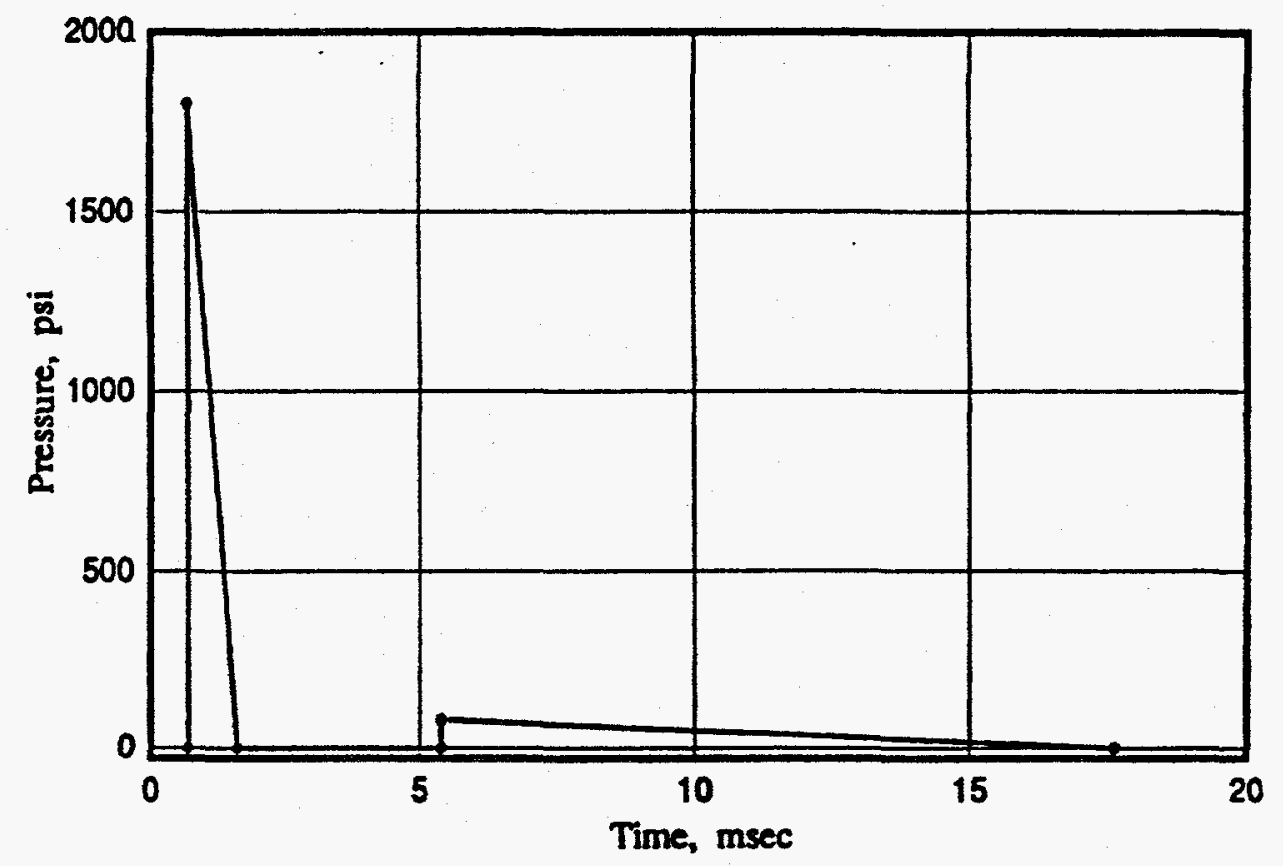

Figure 2. Design Blast Pressure History of the Cylindrical Shell

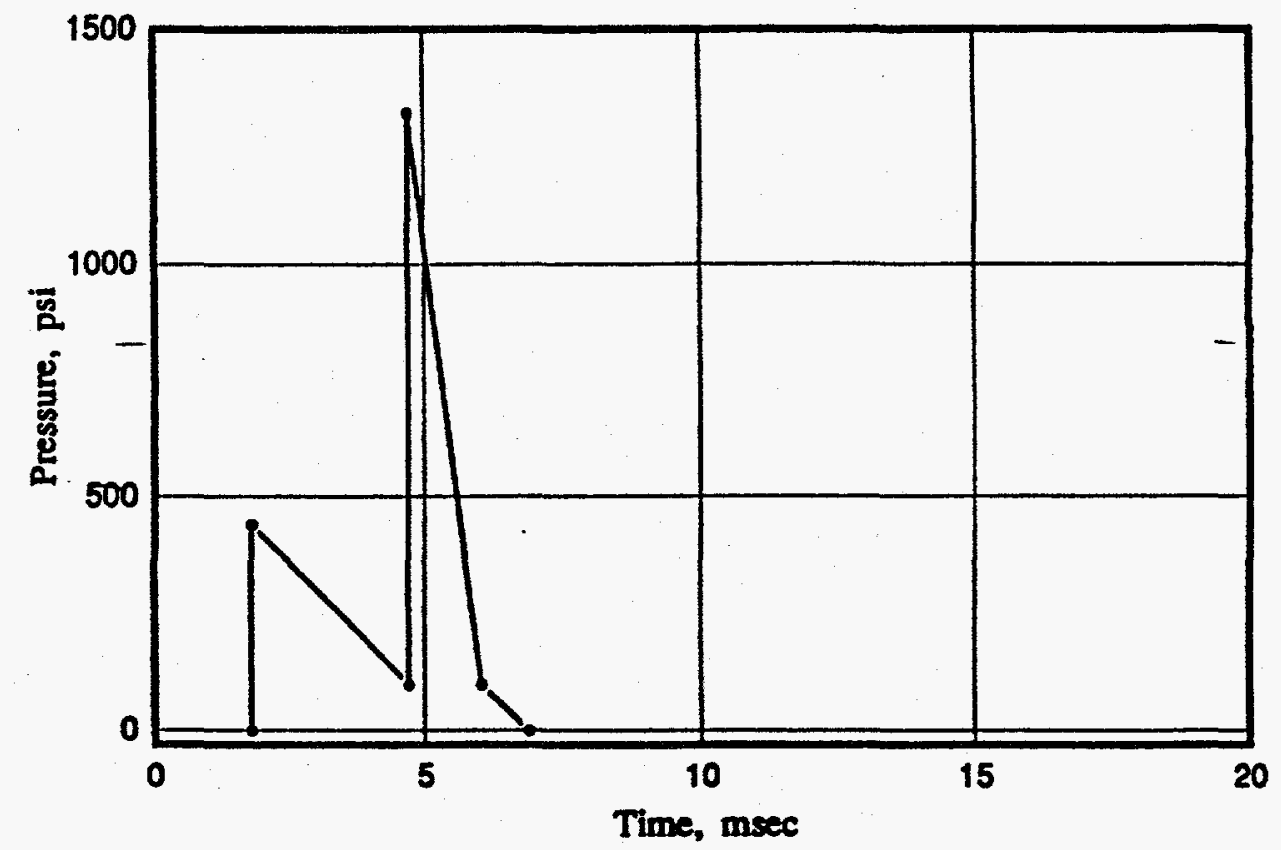

Figure 3. Design Blast Pressure History for the End Caps 
tests. Detailed test procedures were developed and followed in performing the proof tests ${ }^{[6]}$. In addition to the step-by-step test procedures, Reference 6 also described the three types of test required, listed all of the materials, equipment and instrumentation to be used on each type of test, and specified the information to be recorded in the quality control and assurance forms.

The hydrostatic pressure test provided an initial static check on the capacity of the vessel and an operational check of the strain instrumentation. This test was performed prior to the floor being installed in the vessel. Approximately 12,400 gallons of water were used to fill the chamber for the hydrostatic test. Equivalent static capacities for the shell, heads and the door were determined for use in the hydrostatic test. The maximum hydrostatic pressure used for this test was 780 psig based on the design of the door, the chamber component with the lowest static capacity. For the other components having higher static capacity, the data were extrapolated linearly (elastic response) to determine the strain or stresses at higher hydrostatic pressures than the maximum test pressure of $780 \mathrm{psig}$. The strain data were recorded at nominal pressure increments of $0,150,300,450,600$ and 780 psig, both on pressure increase and decrease.

Three pneumatic air leak tests were performed in conjunction with the explosion proof tests. These leak tests showed that the vessel was tight and free of leaks from the quasi-static gas pressure that is generated by the design explosive weight. A static internal pressure of 156 psi, equal to $125 \%$ of the design gas pressure, was applied during the air leak tests. This pressure was required to be held in the vessel for four hours with no drop in pressure. In addition, soap bubble inspections during the tests confirmed no air leaks were present. The first air leak test was performed after complete fabrication and total assembly of the vessel, and just prior to the explosive tests. After the first of the two $22-\mathrm{Ib}_{\mathrm{TNT}}(10-\mathrm{kg})$ explosion proof test, the second air leak test was performed. The third and final air leak test took place after the second explosion proof test. All air leak tests were performed successfully.

Two full design charge weight $\left(22 \mathrm{lb}_{\mathrm{TNT}}\right)$ explosion tests were required to show the performance of the vessel at its rated explosive charge capacity and to demonstrate that the response to this charge was in the elastic range. Although not required by the statement-ofwork (SOW), three additional explosion tests were performed with smaller explosive weights to gradually increase the dynamic loading on the vessel, to serve as operational and diagnostic checks on the measurement systems, and to obtain additional data and insight on the blast loads and the response of the vessel. For these three preliminary explosion tests, two charges equivalent to $5 \mathrm{lb}(2.27 \mathrm{~kg})$ of TNT and one charge equivalent to $10 \mathrm{lb}(4.54 \mathrm{~kg})$ were used. These preliminary tests were fired between the first air leak test and the first full charge explosion proof test.

In all three of the preliminary and the two full charge explosion proof tests spherical charges were located at the geometric center of the cylindrical shell. The center of the charge was 42 inches from the floor, 69 inches from the cylindrical shell, and centered on the longitudinal center line. The high explosive spheres were made from Composition C-4 explosive using hemispherical molds. The TNT equivalency of C-4 is 1.127 based on the calculated heats of denotation assuming the final state of the water products to be liquid. The actual weights of the charges used to represent 5,10 , and $22 \mathrm{lb}$ of TNT were $4.44,8.87$ and 
$19.52 \mathrm{lb}$ of $\mathrm{C}-4$, respectively. The spherical charges were initiated using exploding bridgewire detonators Model RP-83 made by Reynolds Industries, Inc.

\section{TRANSDUCER LOCATIONS AND MEASUREMENT SYSTEMS}

The blast pressures loading the vessel and its dynamic response were monitored with an extensive array of measurements that included thirty-three strain channels, four blast pressure channels, two gas pressure channels, and three displacement channels. Measurement locations were selected for each type of measurement and these are identified in Figures 4 and 5 which show four views of the containment vessel. The strain gage locations on these views are identified by the labels S1-S33 and include the sensing orientation of the strain element for a single strain gage, or each element for a two- or three-element strain gage rosette. The blast pressure gages were mounted internally at the center of aluminum blanks used to cover four of the viewports. These pressure transducer locations are labeled BP1-BP4. The two quasistatic gas pressure locations are labeled QP1 and QP2 and the three displacement (noncontact proximity) transducer locations are labeled D1-D3.

The strain gages identified by the labels S1-S33 were mounted on the outside surface of the vessel as close to points of peak predicted stress as the hardware attached to the vessel would allow. Four three-element rectangular rosette strain-gages were placed on the forward end cap near the corner of the door frame, where the finite element model had indicated a high stress concentration; a total of eight two-element orthogonal rosette strain-gages were placed on the aft end cap, the cylindrical shell, and the blast door; and five single element strain-gages were placed primarily on the door frame. Strain gage locations were selected based primarily on the explosion blast design analyses of the various parts of the chamber. The same strain gage locations were used on the hydrostatic test.

Blast pressure measurements labeled BP1-BP4 in Figures 4 and 5 were made in the middle of the aft end cap (without the door) and at three locations on the shell including two symmetrical measurements along the cross section through the center of the vessel where the explosive charge was located. The two quasi-static gas pressure measurements are not location sensitive and for convenience were made through two of the top ports in the vessel. The SOW and the Test Plandid not require any displacement measurements. However, in the course of preparing to perform the proof tests, a decision was made to make three displacement measurements on the blast door and door frame at locations labeled D1-D3.

The data from each of the explosion tests were recorded on two, 28-track, Wideband II magnetic tape recorders. The data were then digitized using two, four channel transient oscilloscopes and transferred to a desk top computer. Subsequently, final report plots were produced, scaled and properly labeled with the test number, measurement location, and corresponding engineering units. More details on the transducers and instrumentation used on the proof tests are found in Reference 7 along with all the recorded data plots.

To obtain valid data, several quality control and assurance procedures were followed in instrumenting the containment vessel and in performing the proof tests. Common practice 


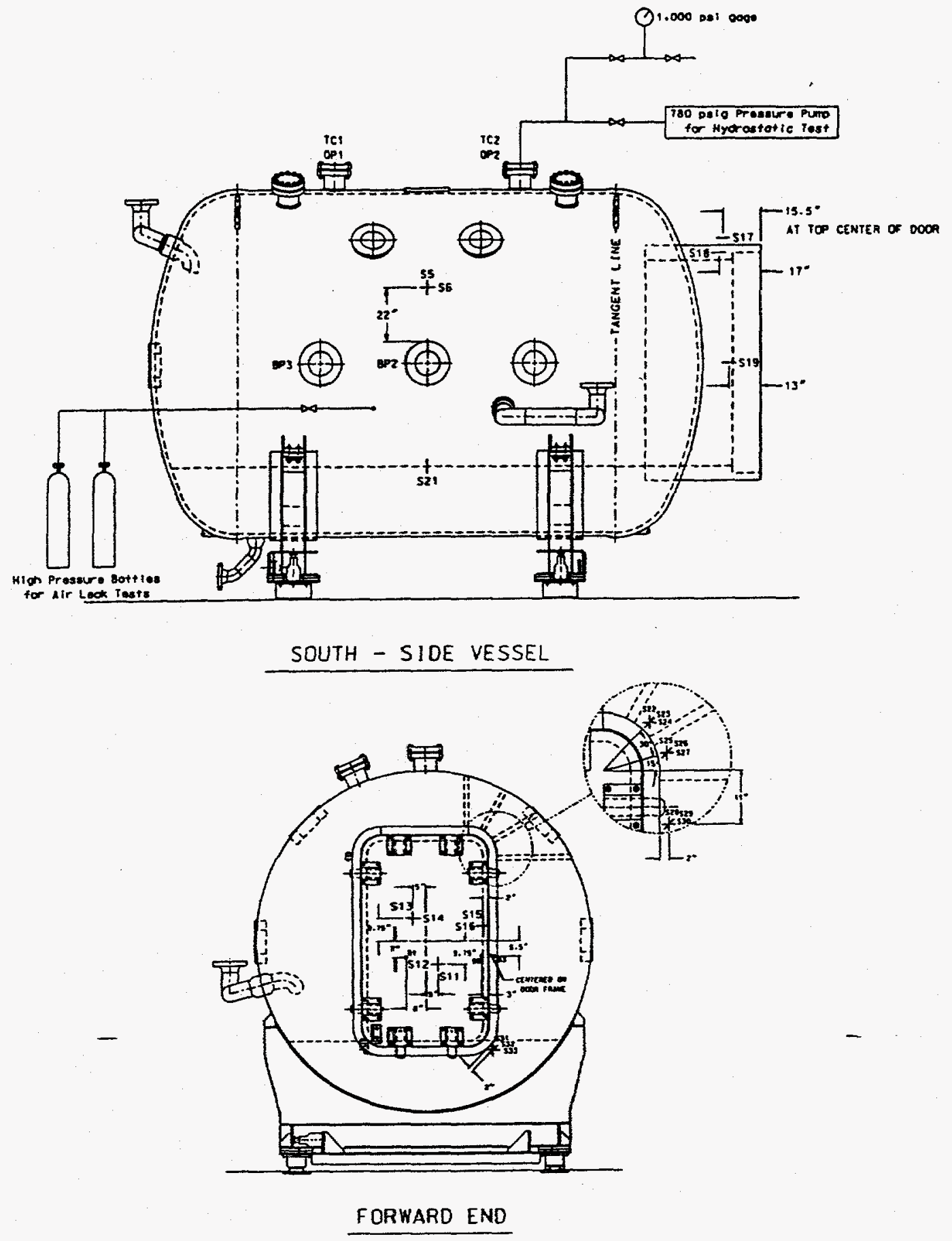

Figure 4. LANL Containment Vessel Measurement Locations 


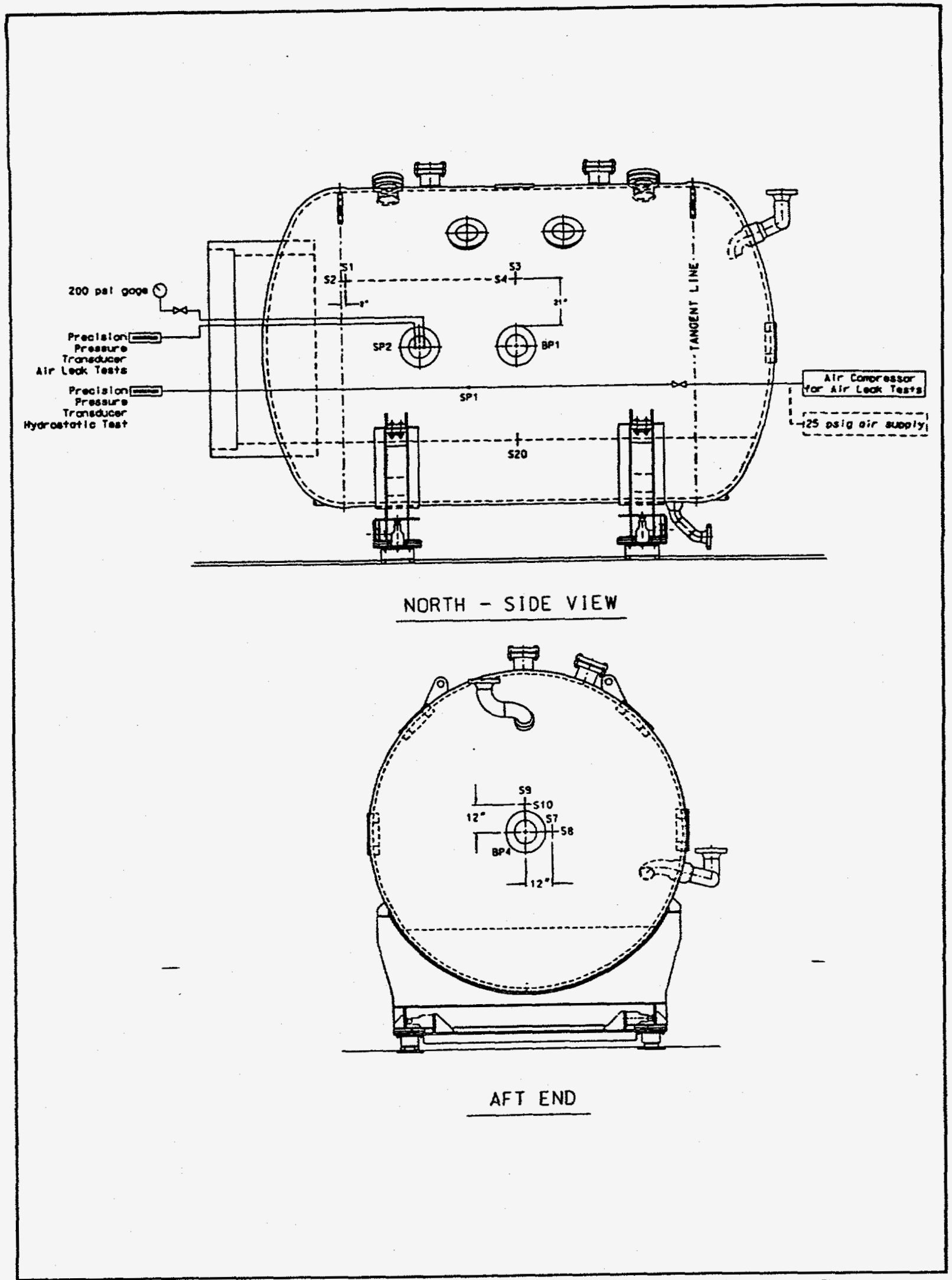

Figure 5. LANL Containment Vessel Measurement Locutions (Continued) 
steps for measurement systems such as using instrumentation and transducers that were in good working order and recently calibrated, characterizing the transient response of the measurement system, and systematically measuring installed strain gage resistances and isolation resistances were utilized during the entire testing sequence. In addition, other less commonly used internal checks were built in into the test procedures and implemented, particularly during the explosion tests. These included the shunt calibration of all the strain gage and piezoresistive channels to check linearity and gain settings, the recording the steady state noise levels for all channels prior to transient stimuli input, the recording of amplitude levels from any undesired outputs from some of the installed strain gages which were monitored with the excitation voltage switched to zero during some of the preliminary explosives tests, and the recording the output of check channels in which a similar strain gage or pressure transducer was not exposed to the transient stimulus.

\section{EXPERIMENTAL RESULTS AND DISCUSSION}

\section{Hydrostatic Test}

As previously mentioned, strain data were recorded on the hydrostatic test at several nominal pressure increments ranging from 0 to 780 psig, both on pressure increase and decrease. Figure 6 shows examples of the circumferential and longitudinal strains measured on the cylindrical shell with strain gage elements S3 and S4, respectively. The corresponding biaxial stresses computed from these two orthogonal strains, a modulus of elasticity of $29,000,000$ psi and a Poisson's ratio of 0.3 are shown in Figure 7 and labeled "hoop" and "long." Similarly, the strains measured with the three elements (S22, S23, and S24) of a $45^{\circ}$ rectangular rosette are shown in Figure 8 . The principal stresses (labeled $P_{\max }$ and $P_{\min }$ ) calculated from these strains are plotted in Figure 9.

In general, the measured strains from the hydrostatic pressure test were quite repeatable, and linear. At locations that could respond without localized constrains, the measured strains matched the expected amplitudes very well. The corresponding stresses, as would be expected, showed similar behavior. For example, the circumferential and longitudinal strains and stresses on the shell measured at locations S3 and S4 at a pressure of 780 psig compared very well with the pretest estimates as shown in Table 1.

Table 1. Hydrostatic Pressure Test Results

\begin{tabular}{|c|c|c|c|c|c|c|}
\hline $\begin{array}{c}\text { Pressure } \\
(p s i g)\end{array}$ & $\begin{array}{c}\text { Strain } \\
\text { Element }\end{array}$ & Orientation & $\begin{array}{c}\text { Pretest } \\
\text { Strain } \\
\text { Estimate } \\
(\mu \text { in/in })\end{array}$ & $\begin{array}{c}\text { Measured } \\
\text { Strain } \\
(\mu \text { in/in })\end{array}$ & $\begin{array}{c}\text { Pretest } \\
\text { Stress } \\
\text { Estimate } \\
(p s i)\end{array}$ & $\begin{array}{c}\text { Measured } \\
\text { Biaxial } \\
\text { Stress } \\
(p s i)\end{array}$ \\
\hline \hline 780 & $\mathrm{S3}$ & Hoop & 1052 & 1061 & 35,880 & 36,100 \\
\cline { 2 - 7 } & $\mathrm{S4}$ & Long. & 247 & 239 & 17,940 & 17,800 \\
\hline
\end{tabular}




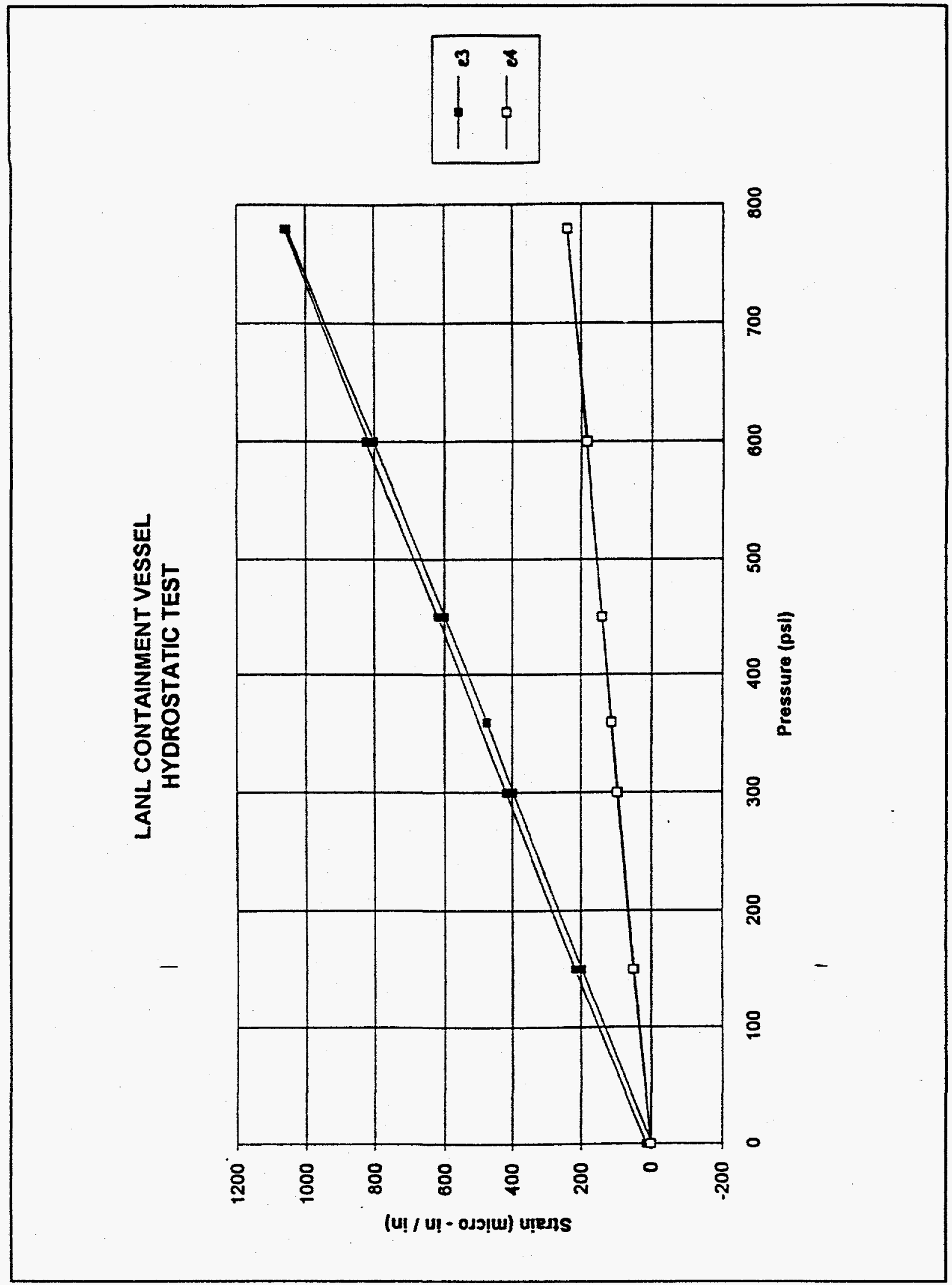

Figure 6. Hydrostatic Test Shell Strains Measured with Two Element Rosette 


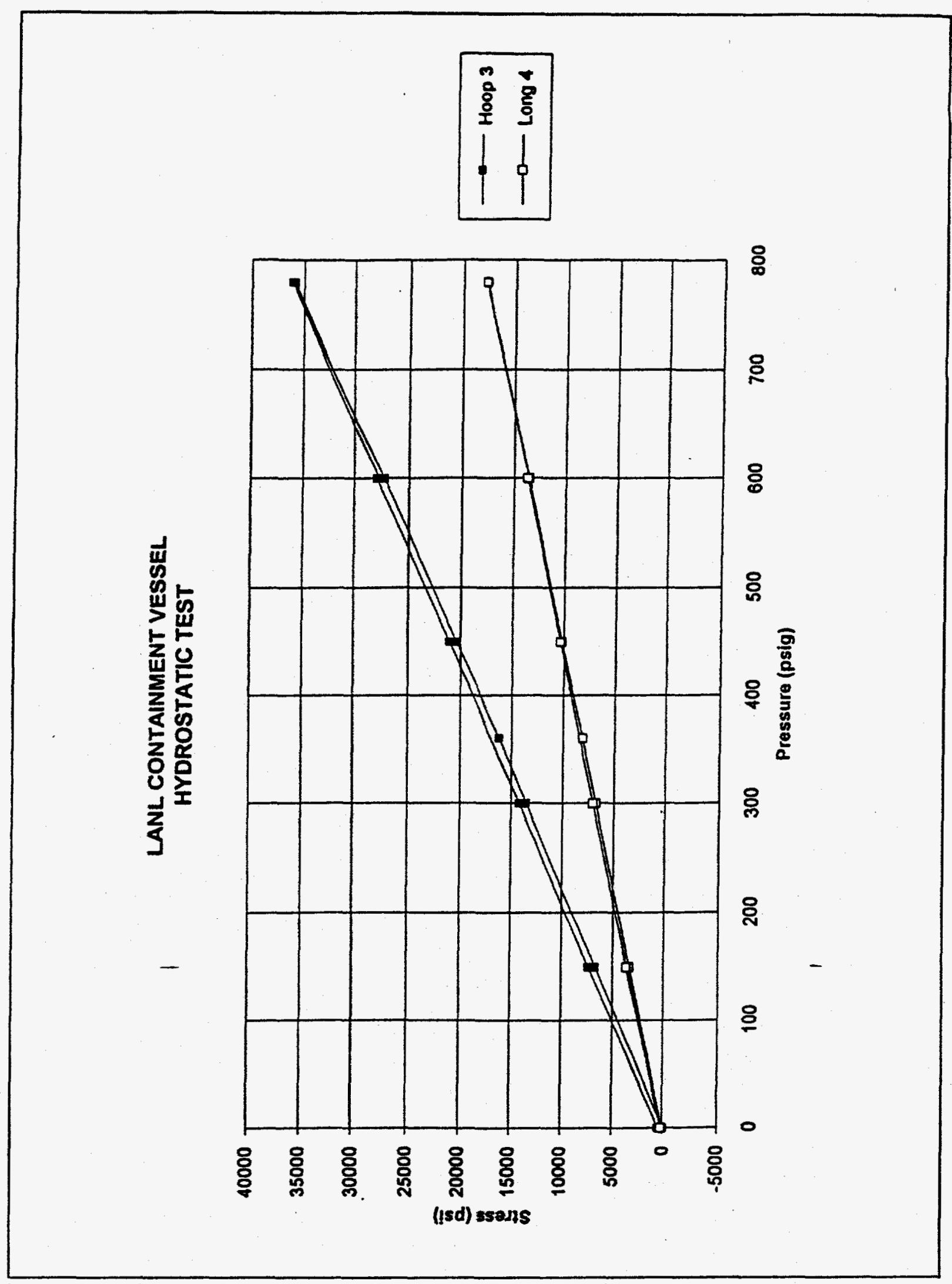

Figure 7. Hydrostatic Test Biaxial Stresses on the Shell 


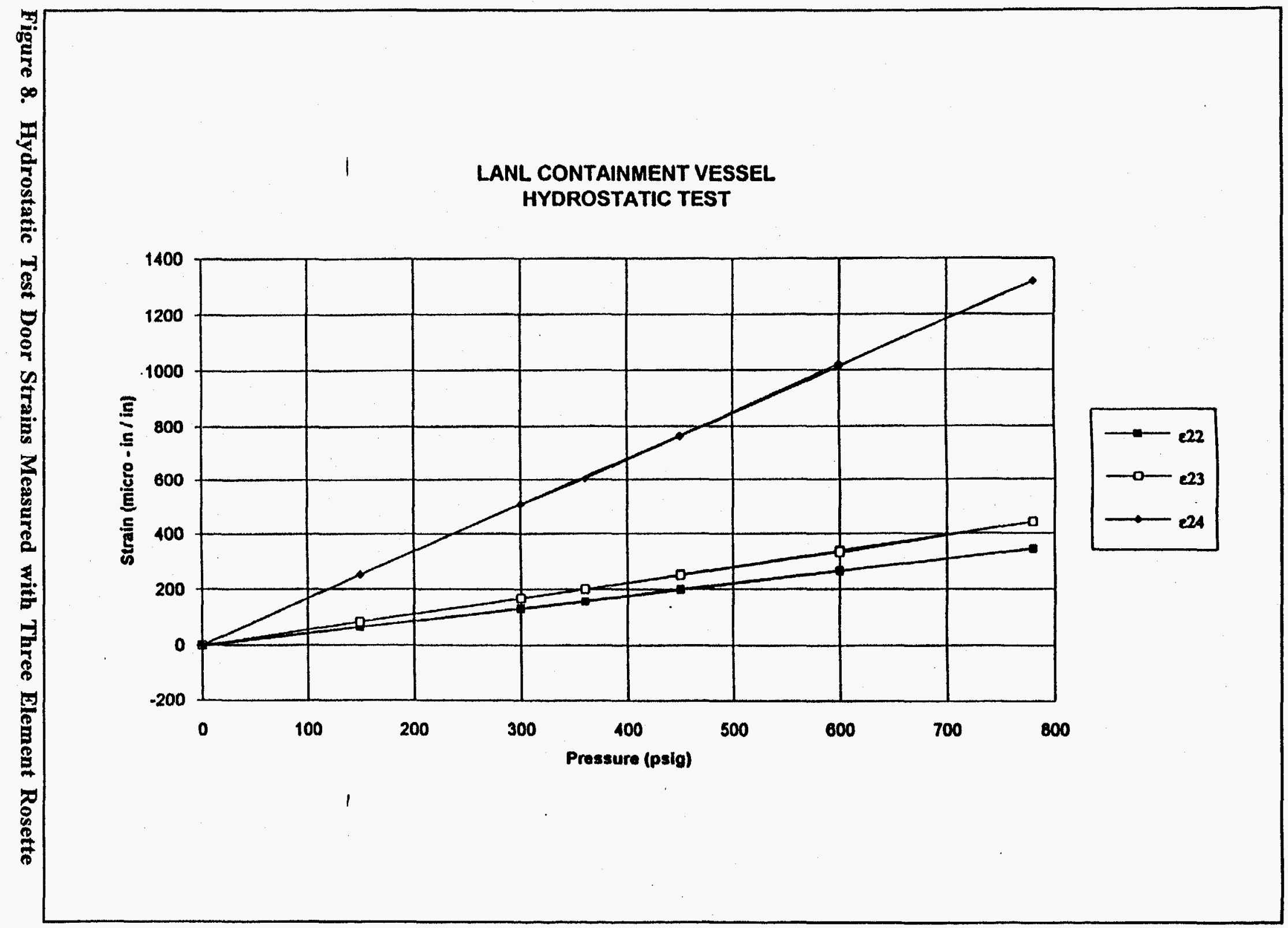



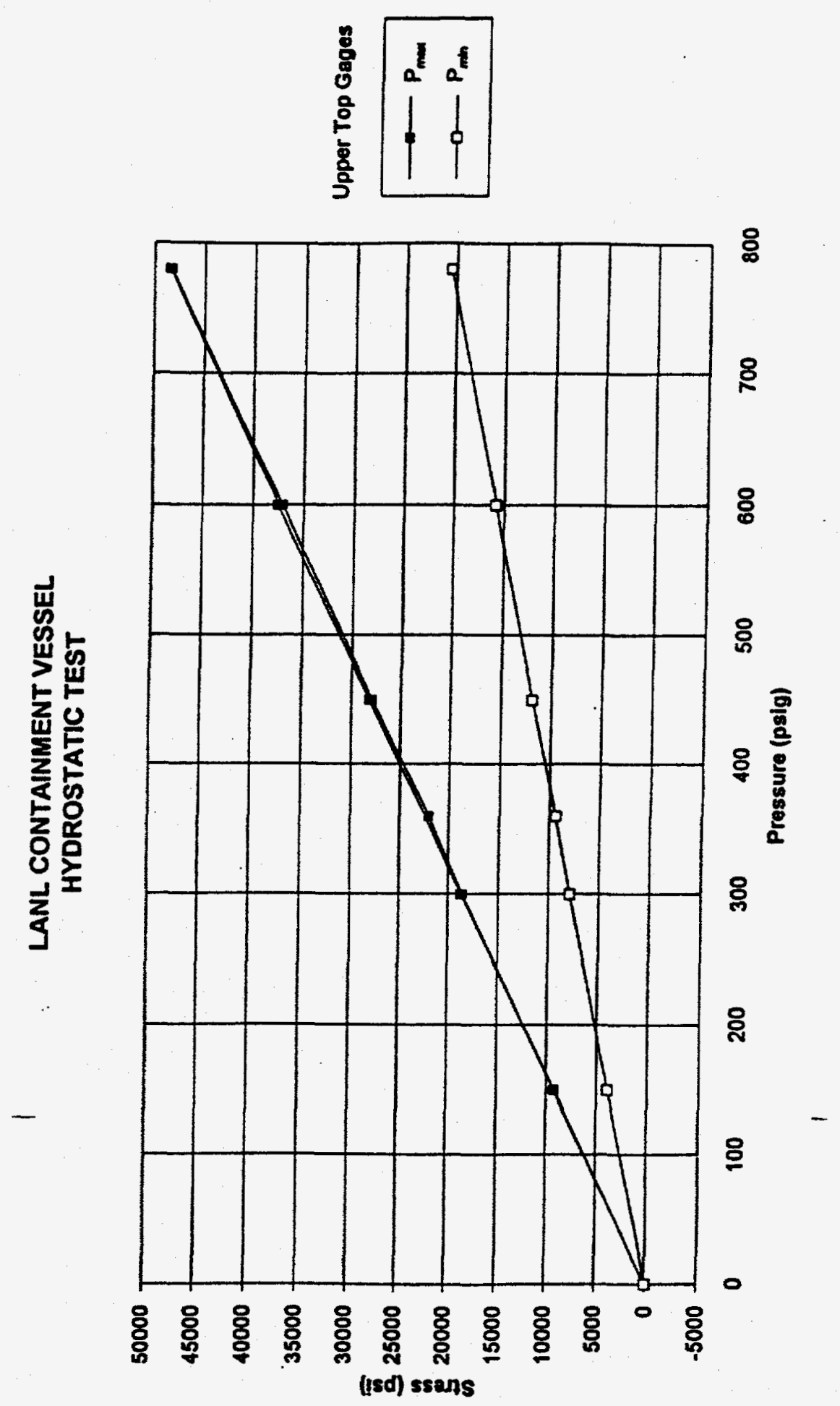

Figure 9. Hydrostatic Test Principal Stresses on the Door Frame 
The largest biaxial stress on the endcap was 38,800 psi from the data at locations S9 and S10. The largest calculated principal stress from the three-element rosettes was 53,600 psi from strain elements S31, S32, and S33. The largest biaxial stress on the door was 80,000 psi in the horizontal direction from strain elements S13 and S14. A symmetrical measurement at locations S11 and S13 resulted an almost identical biaxial stress of 79,100 psi.

\section{Explosion Tests}

The five explosion tests were instrumented with 42 data channels which included 33 of strain, 4 of blast pressure, 2 of quasi-static pressure, and 3 of displacement measurements. Of the 210 total measurements attempted on the 5 tests, $96 \%$ successfully recorded complete time histories of the tests. An additional sixteen data traces of blast impulse from the integration of the blast pressure records were also obtained successfully. The recorded data were very self-consistent and repeatable.

Analysis of the strain data indicated excellent replication for the two $22 \mathrm{lb}_{\mathrm{TNT}}$ proof tests. Comparisons trace-by-trace show not only similar amplitudes but almost identical timehistories. For example, Figure 10 shows the strain records for strain element $\mathbf{S} 3$ on the shell from both proof tests. Figure 11 is a similar set of records of the dynamic response of the end cap at location S9, and Figure 12 shows the records from location S12 on the door. These strain data show a very definite difference in the vibration frequencies of the cylindrical shell, elliptical head and door plate. The largest strains measured on the explosion proof tests were $2282 \mu \mathrm{in} / \mathrm{in}$ on the door, $1118 \mu \mathrm{in} / \mathrm{in}$ on the shell, and $1636 \mu \mathrm{in} / \mathrm{in}$ on the head. All of these values are well below the strain corresponding to the minimum yield stress of the HY-100 steel. Stresses were computed for several of the two- and three-element rosettes to determine the peak stresses on the vessel during the explosive tests. The measured biaxial strains were used to compute corresponding biaxial stresses in the direction of the strain elements at locations S3 through S14. Maximum principal stresses as a function of time were computed for the three-element rosettes corresponding to strain elements S25, S26, S27 and S31, S32, S33. The resulting peak biaxial and principal stresses for the two $22 \mathrm{lb}_{\mathrm{TNr}}$ proof tests are shown in Table 2. Again, the repeatability of the vessel response data is obvious. The largest stresses computed from the strain gage rosettes were $77,100 \mathrm{psi}$ on the door, $35,000 \mathrm{psi}$ on the shell and 63,700 psi on the head. All these values were well below the minimum yield stress of 100,000 psi for HY-100 steel.

The blast pressure transducers produced reasonably good time histories. The blast pressure records were digitized at two sampling rates. A rate of $1 \mu$ s per sample was used to obtain accurate peak pressures during the first $4 \mu \mathrm{s}$ of the transient event. A rate of $5 \mu \mathrm{s}$ per sample was used to obtain impulse values to $10 \mathrm{~ms}$, the time period used to estimate the design loads. The blast loads, in terms of pressure and impulse histories, for one of the proof tests measured on the vessel shell at the mid-span location BP2 are shown in Figure 13. The impulse, which is a measure of the total energy in the blast load, is equal to the integral of the area under the pressure-time history. Also shown with these two data traces are the first 10 $\mathrm{ms}$ of the predicted pressure and impulse histories used in the design of the cylindrical shell of the vessel (see Figure 2). The peak dynamic response of all vessel components occurred 


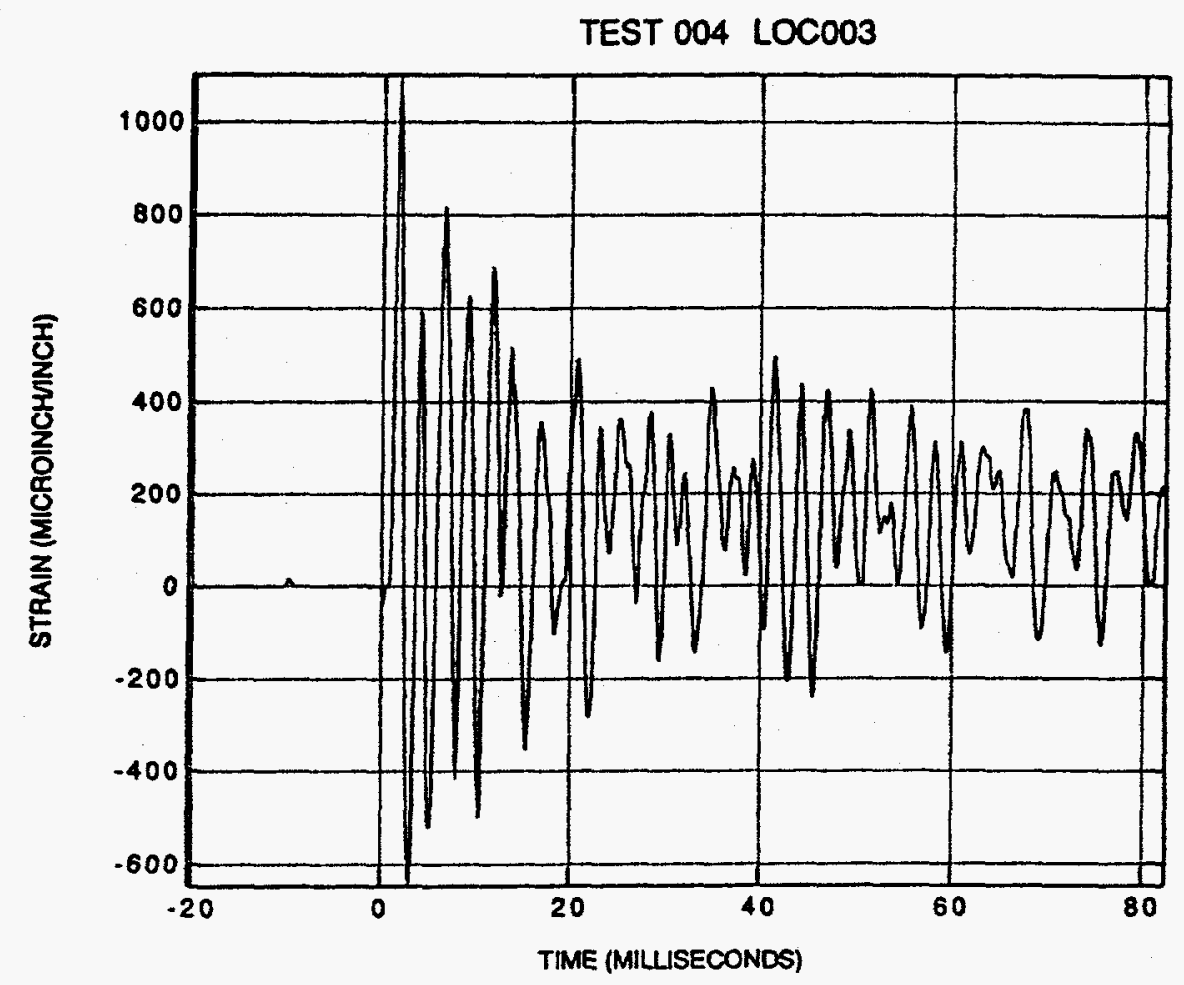

TEST $005 \quad$ LOC003

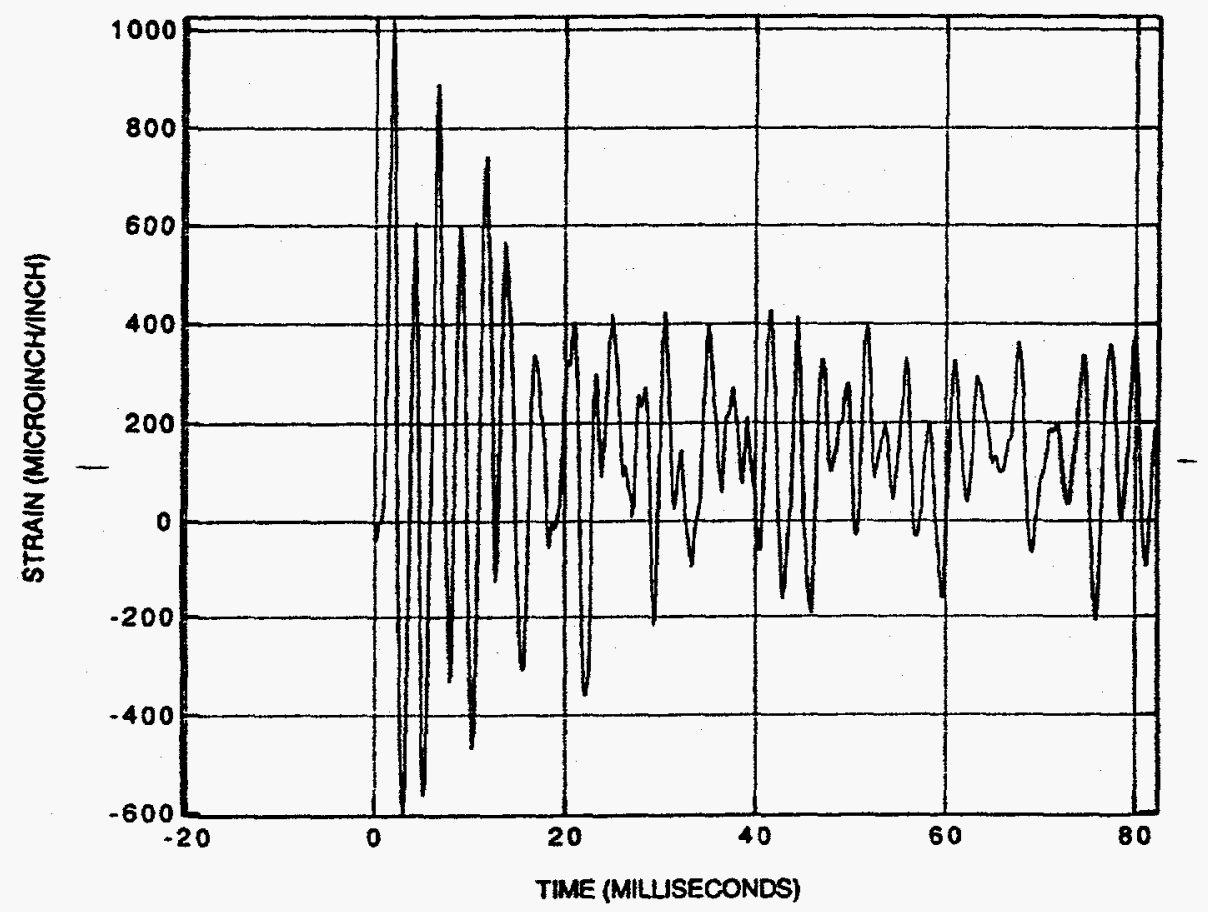

Figure 10. Explosion Test Circumferential Strains on the Shell 


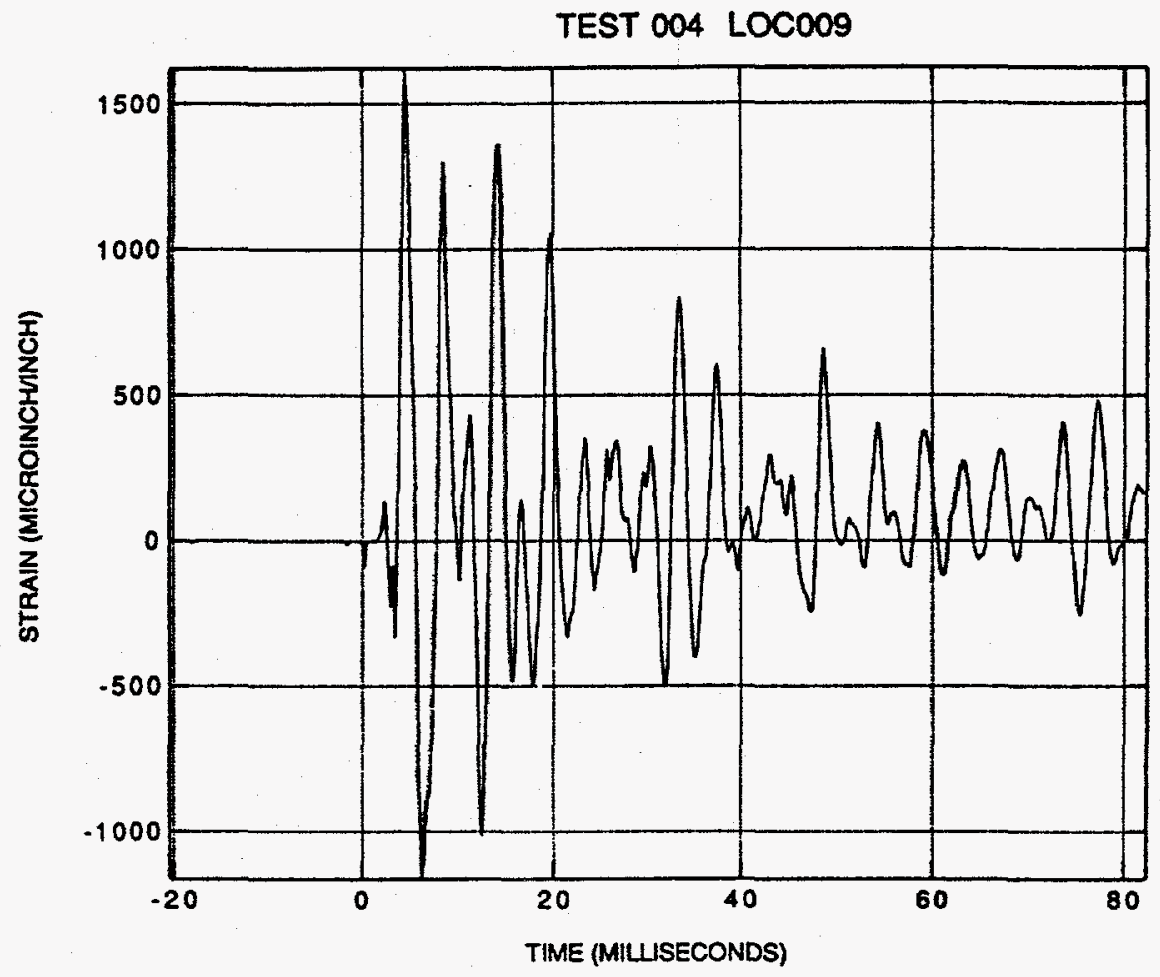

TEST $005 \quad$ LOC009

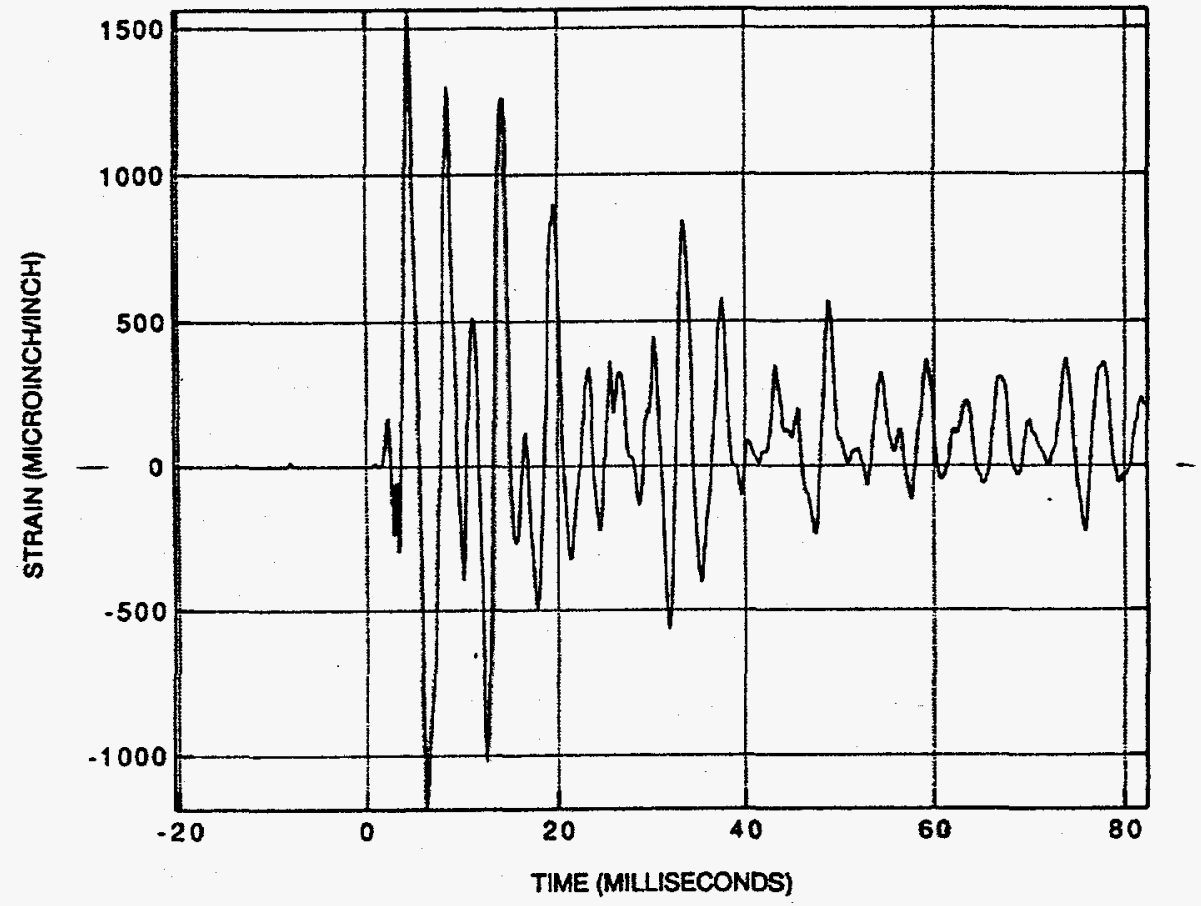

Figure 11. Explosion Test Radial Strains on the End Cap 


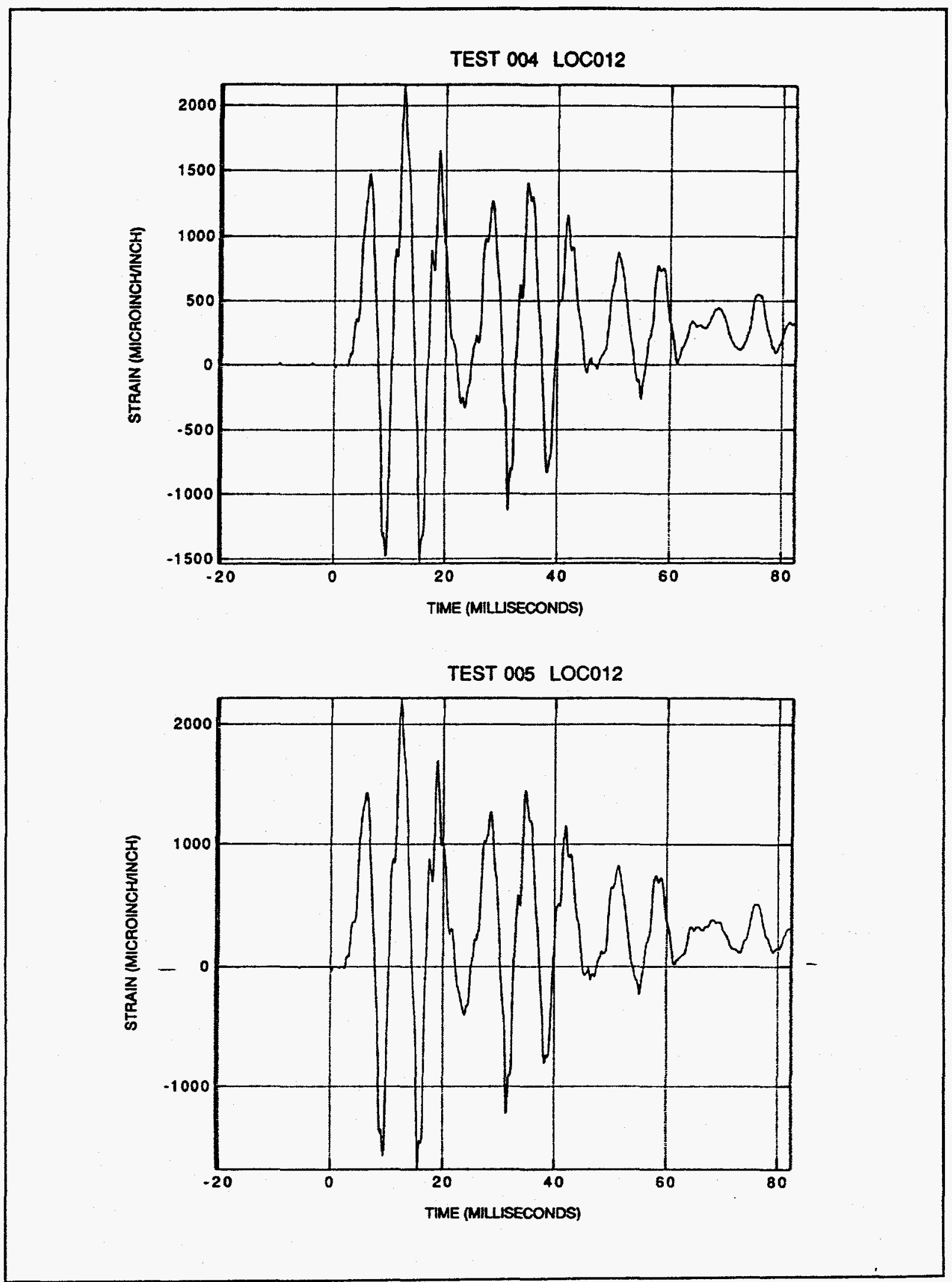

Figure 12. Explosion Test Longitudinal Strains on the Door 

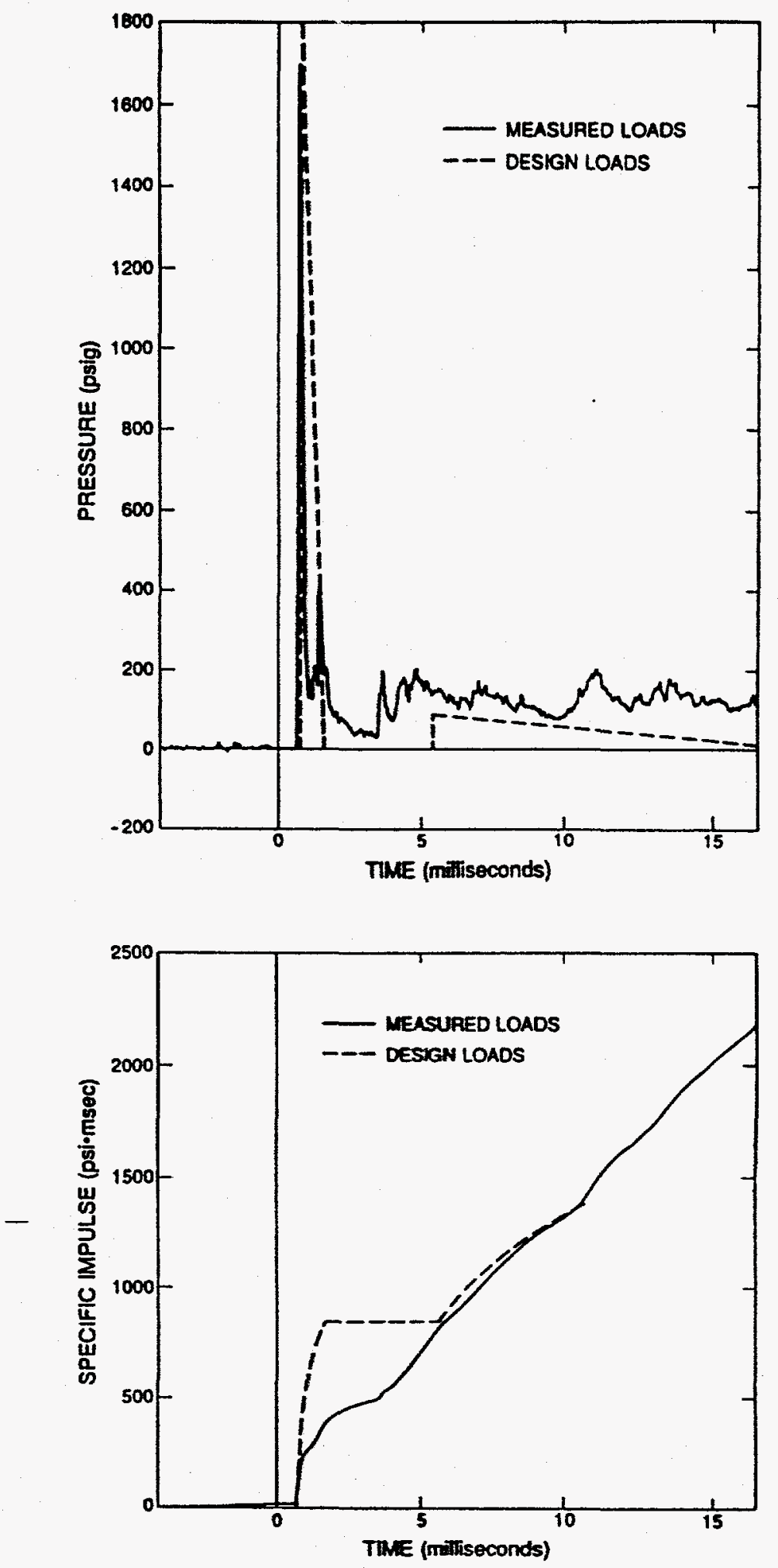

Figure 13. Measured and Design Blast Loads on the Mid-span of the Shell 
well within $10 \mathrm{~ms}$ after the arrival of the shock wave. The design pressure time-history is similar in form to the pressure test data, but the durations and amplitudes of the pressure pulses within the pressure history differ. The effect of these differences on the impulse is apparent in Figure 13, which also shows that the impulse measured early in time (during the first $5 \mathrm{~ms}$ ) was significantly less than the design impulse. The impulse in the predominant pressure pulse, with the highest peak pressure, in the two measured pressure histories is between one-third and one-half the design impulse. However, partially compensating differences between the measured and design pressure histories later in time caused the average of the measured impulses of $1190 \mathrm{psi}-\mathrm{ms}$ to almost match the design value at $10 \mathrm{~ms}$ after the arrival of the initial shock front.

Table 2. Peak Stresses from the Strain Data Measured on the Explosion Proof Tests

\begin{tabular}{|c|c|c|c||}
\hline & & \multicolumn{2}{|c|}{$\begin{array}{c}\text { Peak Stresses (psi) } \\
\text { for Two Proof Tests }\end{array}$} \\
\hline \hline 03,04 & Stress Directions & 35,000 & 31,400 \\
\hline 04,03 & Hoop & 15,200 & 15,400 \\
\hline 05,06 & Longitudinal & 30,550 & 28,700 \\
\hline 06,05 & Hoop & 20,700 & 20,700 \\
\hline 07,08 & Longitudinal & 59,900 & 58,200 \\
\hline 08,07 & Tangential & 61,600 & 60,700 \\
\hline 09,10 & Radial & 63,700 & 62,300 \\
\hline 10,09 & Radial & 59,500 & 56,800 \\
\hline 11,12 & Tangential & 42,700 & 43,900 \\
\hline 12,11 & Longitudinal & 74,600 & 76,100 \\
\hline 13,14 & Transverse & 43,700 & 47,300 \\
\hline 14,13 & Longitudinal & 75,500 & 77,100 \\
\hline $25,26,27$ & Transverse & 32,800 & 26,600 \\
\hline $31,32,33$ & Principal & 30,400 & 31,600 \\
\hline
\end{tabular}

Figure 14 shows the pressure and impulse histories measured at location BP4 in the center of the aft end cap (without the door) for one of the $22 \mathrm{lb}_{\mathrm{TNT}}$ explosive tests. Also shown in these figures are the first $10 \mathrm{~ms}$ of the pressure and impulse histories used for design of the blast vessel components on both end caps (see Figure 3). The form of the design pressure 

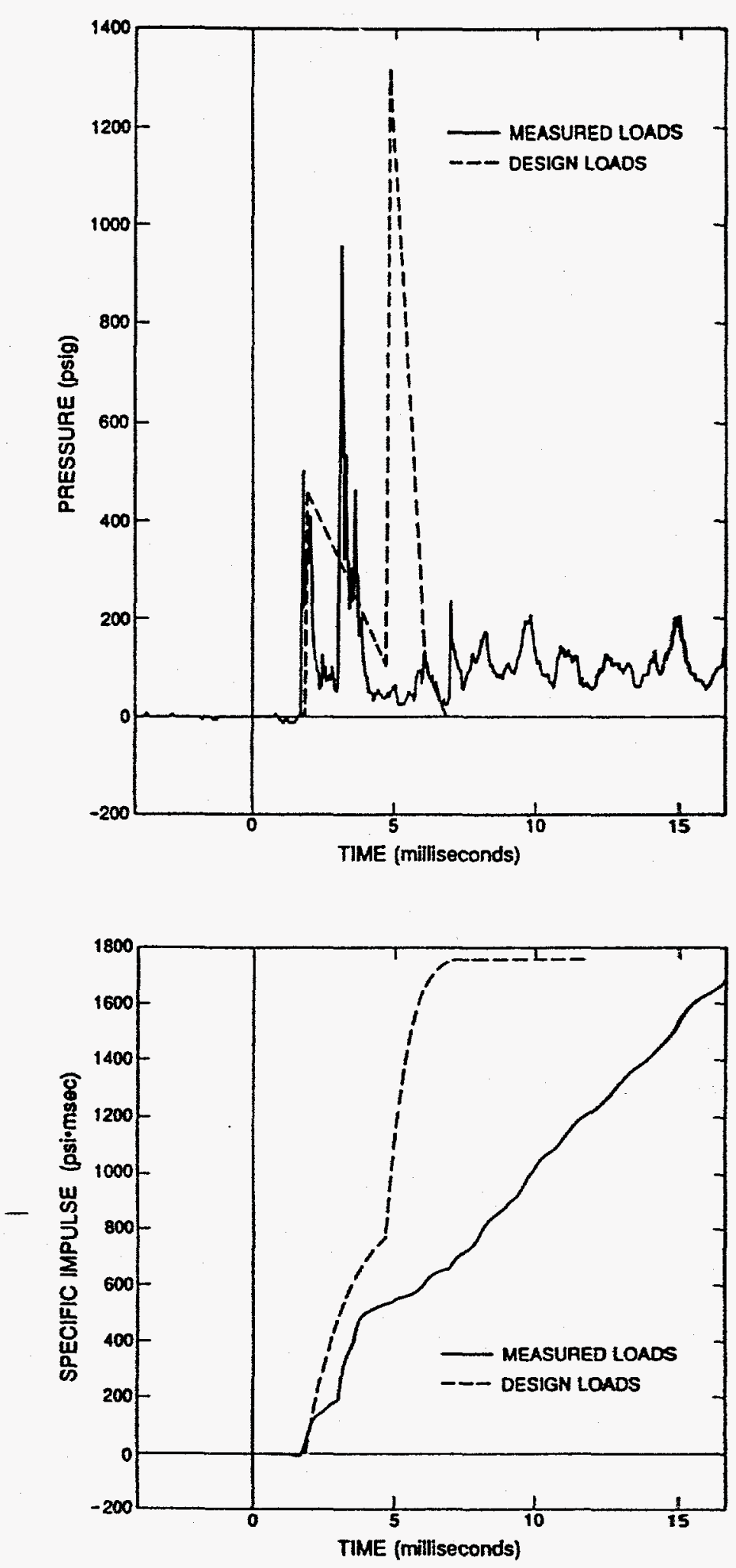

Figure 14. Measured and Design Loads at the Center of Vessel Cap 
history is again generally similar to what was measured during the test. However, significant differences are present for some of the arrival and duration times which, in turn, cause differences in the impulse-time histories. The impulse in the two predominant pressure pulses of the measured pressure history, which primarily drive the structural response, are between one-quarter and one-third the design impulse. However, since there are two significant pressure pulses for this case, it is also notable that the arrival times of the measured pulses are much closer together than the two corresponding pulses in the predicted pressure history. At the $10 \mathrm{~ms}$ time after the arrival of the first shock wave, the average impulse of $1150 \mathrm{psi}-\mathrm{ms}$ measured at the center of the head is almost $65 \%$ of the design value. Thus, the design impulsive loads at $10 \mathrm{~ms}$ after the arrival time of the first blast shock were somewhat conservative as was planned in the design process of the vessel.

In general, the quasi-static pressure channels produced very good time histories that were repeatable within each test and for similar tests. For the full charge proof tests the peak amplitudes averaged $109 \mathrm{psig}$ as compared to the design pressure of 125 psig. This again shows the design loads to be slightly conservative. Figure 15 shows one of the gas pressure traces recorded on one of the proof tests. The displacement transducers were added to the test program to gain additional response data for the door. Peak displacements measured ranged from .049 in on the door frame to .266 in on the door plate. These data were also quite good and repeatable. In addition, comparisons of the displacement traces with the strain traces at comparable locations showed identical vibrations frequencies. Figure 16 shows an example of a displacement trace recorded on one of the proof tests.

\section{CONCLUSIONS}

All of the required proof-tests for the LANL firing facility explosion containment vessel were performed successfully. Three types of tests were required: hydrostatic, air leak, and explosion. All tests were conducted as delineated in the Test Procedures ${ }^{[6]}$, with satisfactory results and with the containment vessel performing as specified. On the hydrostatic test, the largest stress calculated from all of the measured strains was 80,000 psi which occurred on the door. This value is well below the minimum yield stress of 100,000 psi for the HY-100 steel used to fabricate the vessel.

The explosion tests were performed very successfully with excellent data return on the 42 data channels recorded on both of the full charge tests as well as on the three preliminary explosion tests. The recorded data from the five explosion tests were very self-consistent and repeatable. Comparisons trace-by-trace showed not only similar amplitudes for similar test conditions, but almost duplicate time-histories. The peak dynamic stresses calculated from the strains measured on the shell, the head and the door were $35,000 \mathrm{psi}, 63,700 \mathrm{psi}$, and 77,000 psi, respectively. All these values were also well below the minimum yield stress for HY-100 steel.

The average blast pressures and impulses measured on the shell and on the head in the two $22 \mathrm{lb}_{\mathrm{TN} T}$ proof tests were both of lower amplitude then the design values. The net result was that a "safety" factor of less than 1.1 was present on the impulse used for the design of the cylindrical shell and of about 1.5 for the impulse used to design the elliptical heads and the door plate. Similarly, the average of the quasi-static pressures measured on the two full charge proof tests were lower by about $13 \%$ than the conservative estimates used for design. The 


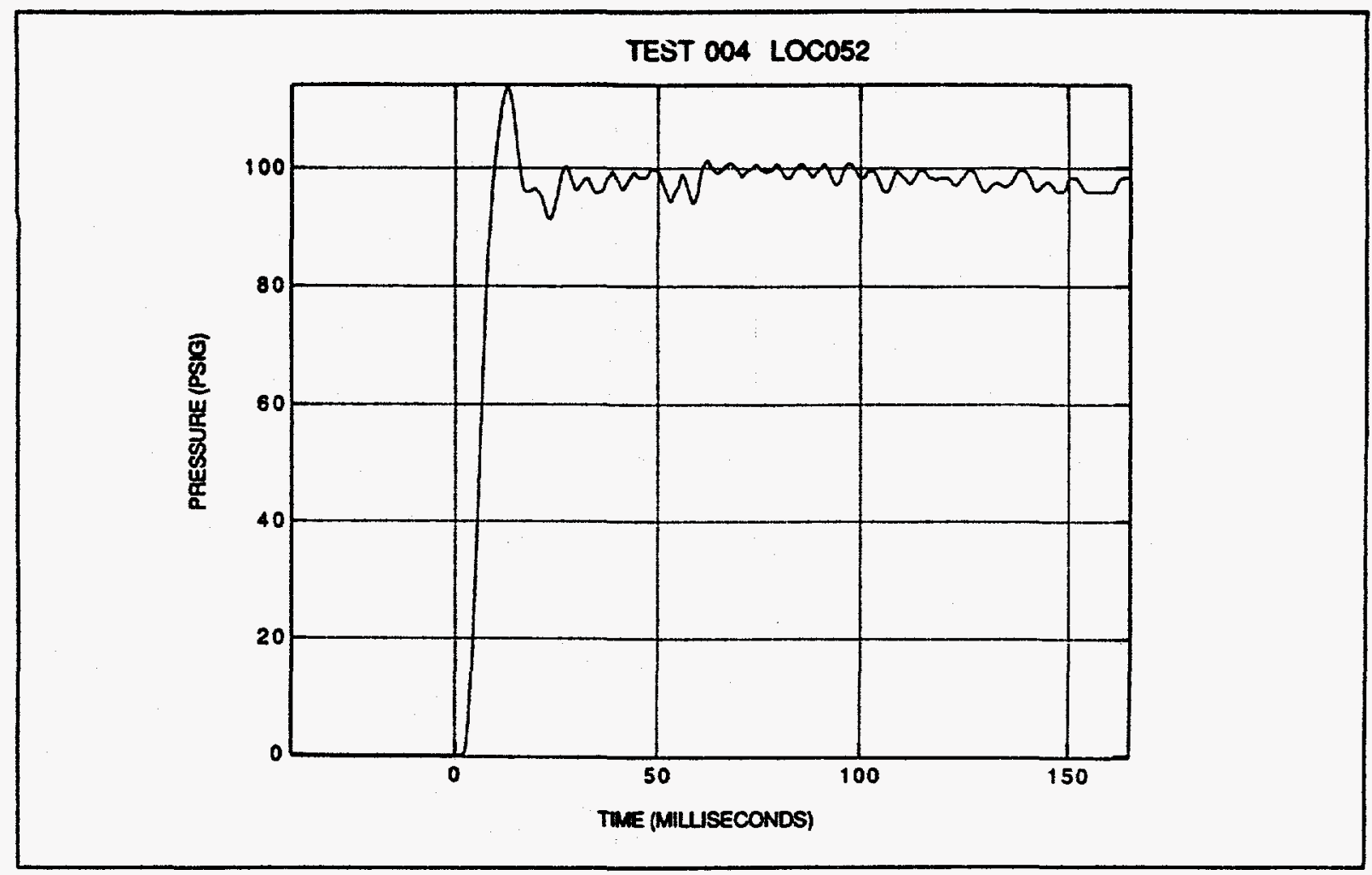

Figure 15. Quasi-Static Pressure Measured on Explosion Proof Test

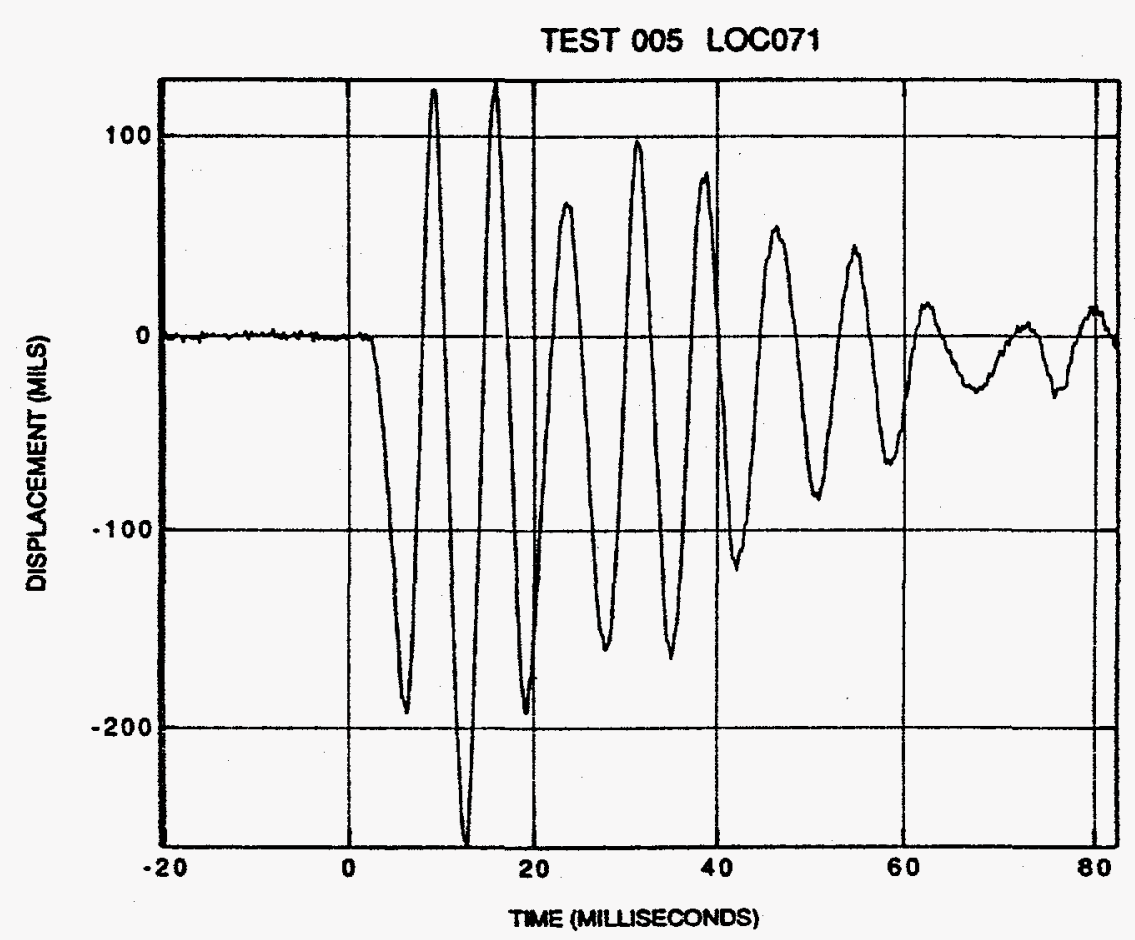

Figure 16. Door Plate Displacement Measured on Explosion Proof Test 
displacement data for the door were quite repeatable for similar test conditions and very similar in time to corresponding door strain records.

In conclusion, prior to delivery and acceptance, the LANL containment vessel passed successfully the three type of proof tests required: a hydrostatic pressure test, three air leak tests, and two $22 \mathrm{lb}_{\mathrm{TNT}}$ design charge explosion tests.

\section{ACKNOWLEDGEMENTS}

The proof tests were performed for the Los Alamos National Laboratory while E.D. Esparza, the Test Engineer, was an employee of Southwest Research Institute. The successful performance of the proof tests was due to the team effort of many individuals working with the authors. M.A. Polcyn was the project manager. E.R. Garcia, Jr., under the direction of Test Engineer, mounted the transducers and strain gages on the vessel, set up the measurement systems, and recorded, digitized, and plotted the explosion test data. M.R. Burgamy made and fired the explosive charges. J.W. Little and E.B. Bowers recorded the hydrostatic test data. F.D. Caroline, R.D. Smith, D. Valles, J. Freer, D. Hendrix, and L. Bybee provided mechanical and test support to perform all of the proof tests. R.D. Young provided the on-site quality assurance on all the tests. W.S. Bielfeld assisted with the data processing and D.A. McKee prepared the drawings of the vessel used in this paper.

\section{REFERENCES}

1. Polcyn, M.A, Esparza, E.D. and Whitney, M.G., "Design of the M-9 Facility Containment Vessel for Los Alamos National Laboratory," Minutes of the 25th Explosives Safety Seminar, Volume IV, Department of Defense Explosives Safety Board, Anaheim, CA, August 1992.

2. Oswald, C.J., Polcyn, M.A and Esparza, E.D., "Dynamic Design and Proof Testing of Blast Containment Vessel," Symposium on Structural Dynamics Produced by HighEnergy Excitations, 1994 ASME Pressure Vessels and Piping Conference, Minneapolis, MN, June 1994.

3 "M-9 Firing Facility Containment Vessel, One Hundred Percent Design Basis Document," prepared for Los Alamos National Laboratory, Subcontract 9-L51-D9320-1, Southwest Research Institute Project 06-4023, San Antonio, TX, 1991.

4. Esparza, E.D. and White, R.E., "Blast Pressure Measurements in Containment Test Cells," Minutes of the 23rd Explosives Safety Seminar, Volume II, Department of Defense Explosives Safety Board, Atlanta, GA, August 1988.

5. Britt, J.R. "Internal Blast Environment from Internal and External Explosions: a User's Guide for BLASTIN, CHAMBER, TUNREF, and BLASTX Codes," Science Applications International Corporation 405-89-3, December 1989. 
6. Esparza, E.D. "Test Procedures for Proof-Testing the M-9 Firing Facility Containment Vessel," Southwest Research Institute Project No. 06-4023, San Antonio, TX, July 1992.

7. Esparza, E.D., "Proof-Tests and Data Report for the LANL M-9 Firing Facility Containment Vessel," Southwest Research Institute Project No.06-4023, San Antonio, TX, December 1992. 